
$\angle$ Research Square
Preprints are preliminary reports that have not undergone peer review.
They should not be considered conclusive, used to inform clinical practice, or referenced by the media as validated information.

\title{
Debridement, antibiotics, irrigation, and retention of the prosthesis with antibiotic-impregnated calcium hydroxyapatite in periprosthetic hip joint infection
}

Hiroki Wakabayashi ( $\nabla$ whiroki@clin.medic.mie-u.ac.jp)

Mie University of Graduate School of Medicine https://orcid.org/0000-0003-0371-911X

Masahiro Hasegawa

Mie University Graduate School of Medicine

Yohei Naito

Mie University Graduate School of Medicine

Shine Tone

Mie University Graduate School of Medicine

Akihiro Sudo

Mie University Graduate School of Medicine

\section{Research article}

Keywords: periprosthetic hip joint infection, Debridement, antibiotics, irrigation, and retention; antibiotic-impregnated calcium hydroxyapatite

Posted Date: August 30th, 2021

DOl: https://doi.org/10.21203/rs.3.rs-842120/v1

License: (1) This work is licensed under a Creative Commons Attribution 4.0 International License. Read Full License 


\section{Abstract \\ Background}

We have developed antibiotic-impregnated calcium hydroxyapatite (CHA) as a novel antibiotic delivery system. Here, we assessed the clinical results of debridement, antibiotics, irrigation, and retention of the prosthesis (DAIR) with antibioticimpregnated CHA for the treatment of prosthetic joint-associated infection (PJI) after total hip arthroplasty (THA).

\section{Methods}

Twelve patients (13 hips) treated with DAIR for PJI after THA at our institution between 1997 and 2017 were retrospectively evaluated. The study group included four men (five hips) and eight women, with an average age of 66.1 (range, 56-90) years. Four patients (five hips) had symptoms of infection within less than 3 weeks; however, eight patients had symptoms of infection over 3 weeks. All patients received DAIR with antibiotic-impregnated CHA in the surrounding bone. In one patient, the cup component revision was performed with one-stage re-implantation because of loosening, but the stem component was retained. In nine patients (10 hips), vancomycin hydrochloride was impregnated in the CHA.

\section{Results}

The average duration of follow-up was 8.3 (range, 2.9-18.6) years. No patients were lost to follow-up. Four patients included in this study died of other causes, with an average follow-up of 6.7 (range, 4.0-12.5) years. Intra-operative cultures were positive in 12 hips. Ten of 12 patients (11 of 13 hips) were successfully treated, and no signs of infection were observed at the latest follow-up. In two of 12 patients (two of 13 hips) for whom treatment failed, infection was successfully treated with two-stage reimplantation. Both patients had diabetes mellitus and symptoms of infection over 3 weeks. Eighty-five percent of patients were successfully treated by DAIR with antibiotic-impregnated CHA. No complications were observed with this antibiotic-impregnated CHA.

\section{Conclusions}

DAIR treatment with antibiotic-impregnated CHA produce a higher rate of success in patients with PJI after THA.

\section{Background}

After removing implants in patients with prosthetic joint-associated infection (PJI), clinicians prefer to insert antibioticimpregnated bone cement in the form of beads or spacers. However, antibiotic-impregnated bone cement is also associated with certain disadvantages, including short duration of drug release [1], very low release rates [1,2], thermal damage to some antibiotics, reduced biocompatibility with the bone for which additional surgery to remove the bone cement is necessary, and possible bone loss adjacent to loose spacers. Moreover, two-stage revision arthroplasty using cementless prostheses cannot be used for antibiotic-impregnated bone cement.

Infection after total hip arthroplasty (THA) remains a severe and costly complication [3, 4]. A regimen of debridement, antibiotics, irrigation, and retention of the prosthesis (DAIR) was recently approved for the treatment of acute PJI. In early PJI, debridement with retention of the implant is another attractive treatment option. This procedure reduces morbidity, length of hospital stay, and medical costs compared with one-stage or two-stage revision arthroplasty [5]. Various risk factors associated with treatment success have been described.

Antibiotic-impregnated calcium hydroxyapatite (CHA) ceramic has recently been developed as a new drug delivery system (Fig. 1A) [6, 7] and has been used for the treatment of PJI after THA. Using this system, all implanted antibiotics are released over a long period, with no trapping of the drug in the composite [6], and high release rates are observed [6]. Using this drug 
delivery system with CHA, we have treated patients with PJI by replacing the modular components (including the femoral head and acetabular insert) and loosening component and retaining the fixed components.

Accordingly, in this study, we aimed to evaluate the clinical results of antibiotic-impregnated CHA used for DAIR treatment or one-stage revision arthroplasty of infected hips.

\section{Materials And Methods}

\section{Patients}

This research was approved by the Institutional Review Board of our institution. Twelve patients (13 hips) treated with DAIR for PJI after THA at our institution between 1997 and 2017 were retrospectively enrolled in this study and followed for more than 2 years after treatment. The study group consisted of four men (five hips) and nine women, with an average age of 66.1 years (range, 56-90 years). The initial diagnoses were osteoarthritis in five patients, rheumatoid arthritis in four patients (five hips), idiopathic osteonecrosis in two patients, and neck fracture in one patient (Table 1).

Table 1

Patient demographics of DAIR treatment

\begin{tabular}{|ll|}
\hline Male 5 hips(4 patients) Female 8 hips & \\
\hline Age(treatment of PJI) & Ave. 66.1y (56-90y) \\
\hline Osteoarthritis(OA) & 5 hips \\
Rheumatoid arthritis(RA) & 5 hips(4 patients) \\
Idiopathic osteonecrosis(ION) & 2 hips \\
Neck fracture(Fx) & 1 hip \\
\hline Follow up periods after treatment of PJI & Ave. 8.3 years $(2.9-18.6$ years) \\
\hline
\end{tabular}

The diagnosis of infection was based on the clinical criteria, including the presence of discharging sinus, frank purulent fluid, or pus found on pre-operative hip aspiration or positive findings on laboratory and histopathological tests. The criteria to define PJI were the presence of a sinus tract communicating with the prosthesis and/or at least two identical positive cultures.

Soft tissue was normal in eight patients (nine hips) and abscessed with fistula in three hips (Table 2). One of the patients with fistula developed a productive fistula 4 days before surgery. 
Table 2

Patient information of DAIR treatment

\begin{tabular}{|c|c|c|c|c|c|c|c|c|c|c|}
\hline Case & Sex & Age & $\begin{array}{l}\text { Diag- } \\
\text { noses }\end{array}$ & $\begin{array}{l}\text { Previous } \\
\text { Surgery }\end{array}$ & $\begin{array}{l}\text { Onset } \\
\text { symptom }\end{array}$ & Organism & $\begin{array}{l}\text { Age of } \\
\text { THA } \\
\text { (months) }\end{array}$ & $\begin{array}{l}\text { The time } \\
\text { from } \\
\text { surgery } \\
\text { to onset } \\
\text { symptom }\end{array}$ & $\begin{array}{l}\text { Antibiotics } \\
\text { in the CHA } \\
\text { blocks } \\
\text { (numbers) }\end{array}$ & $\begin{array}{l}\text { Antibiotics } \\
\text { at } \\
\text { Interim } \\
\begin{array}{l}\text { Period } \\
\text { (weeks) }\end{array}\end{array}$ \\
\hline प & M & 65 & ION & Hemi & $\begin{array}{l}\text { Hip pain, } \\
\text { fever }\end{array}$ & E.coli & 112 & 8 months & $\begin{array}{l}\text { CTM, AMK } \\
\text { (5) }\end{array}$ & $\begin{array}{l}\text { CTM, AMK } \\
\text { (6) }\end{array}$ \\
\hline 2 & $\mathrm{M}$ & 56 & ION & THA & $\begin{array}{l}\text { Hip pain, } \\
\text { fever }\end{array}$ & $\begin{array}{l}\text { Strep. } \\
\text { agalactiae }\end{array}$ & 8 & 3 months & FMOX (5) & $\begin{array}{l}\text { FMOX, } \\
\text { FOM, } \\
\text { CTM, } \\
\text { MINO, } \\
\text { IPM/CS, } \\
\text { PCG (5) }\end{array}$ \\
\hline 3 & $\mathrm{~F}$ & 62 & OA & THA & Chill & MRSA & 31 & 3 months & VCM (2) & $\begin{array}{l}\text { ABK, GM } \\
\text { (9) }\end{array}$ \\
\hline 4 & $\mathrm{~F}$ & 69 & $\mathrm{FX}$ & Hemi & Hip pain & $\begin{array}{l}\text { Stap. } \\
\text { epidermidis }\end{array}$ & 1 & 1 month & $\begin{array}{l}\text { VCM, CTM } \\
\text { (5) }\end{array}$ & $\begin{array}{l}\text { FOMX, } \\
\text { ABK, AMK, } \\
\text { VCM, TEIC } \\
(8)\end{array}$ \\
\hline 5 & $\mathrm{~F}$ & 52 & OA & THA & Hip pain & Stap. aureus & 12 & 2 months & $\begin{array}{l}\text { IPM/CS, } \\
\text { CTM(4) }\end{array}$ & $\begin{array}{l}\text { ABPC, } \\
\text { CLDM, } \\
\text { PIPC, } \\
\text { IPM/CS } \\
(6)\end{array}$ \\
\hline 6 & $\mathrm{~F}$ & 71 & OA & THA & $\begin{array}{l}\text { Fever, } \\
\text { fistula }\end{array}$ & CNS & प & 2 weeks & $\begin{array}{l}\text { VCM, AMK } \\
\text { (3) }\end{array}$ & $\begin{array}{l}\text { SBTPC, } \\
\text { CTM, } \\
\text { IPM/CS } \\
\text { (8) }\end{array}$ \\
\hline 7 & M & 57 & RA & THA & Hip pain & MSSA & 78 & 3 days & VCM (2) & $\begin{array}{l}\text { CEZ, } \\
\text { MEPM, } \\
\text { TEIC (7) }\end{array}$ \\
\hline 8 & M & 71 & RA & THA(rt) & Hip pain & MSSA & 43 & 2 weeks & $\begin{array}{l}\text { VCM, FOM } \\
\text { (3) }\end{array}$ & $\begin{array}{l}\text { CEZ, PIPC, } \\
\text { TEIC, } \\
\text { LVFX, } \\
\text { CLDM, } \\
\text { RFP (6) }\end{array}$ \\
\hline 8 & $\mathrm{M}$ & 71 & RA & THA(It) & Hip pain & MSSA & 36 & 2 weeks & $\begin{array}{l}\text { VCM, FOM } \\
\text { (3) }\end{array}$ & $\begin{array}{l}\text { CEZ, PIPC, } \\
\text { TEIC, } \\
\text { LVFX, } \\
\text { CLDM, } \\
\text { RFP (6) }\end{array}$ \\
\hline 9 & $\mathrm{~F}$ & 63 & $\mathrm{OA}$ & THA & $\begin{array}{l}\text { Hip pain, } \\
\text { fever, } \\
\text { fistula }\end{array}$ & MSSA & 36 & 7 months & $\begin{array}{l}\text { VCM, FOM } \\
\text { (3) }\end{array}$ & $\begin{array}{l}\text { CLDM, } \\
\text { TEIC, } \\
\text { VCM, RFP } \\
(7)\end{array}$ \\
\hline 10 & $\mathrm{~F}$ & 74 & RA & THA & Swelling & E.coli & 84 & 6 months & $\begin{array}{l}\text { VCM, FOM } \\
\text { (3) }\end{array}$ & $\begin{array}{l}\text { CEZ, } \\
\text { MEPM, } \\
\text { IPM/CS, } \\
\text { RFP (6) }\end{array}$ \\
\hline 11 & $\mathrm{~F}$ & 64 & RA & THA & Swelling & - & 48 & $\begin{array}{l}3.5 \\
\text { weeks }\end{array}$ & VCM (3) & $\begin{array}{l}\text { CEZロ } \\
\operatorname{LVFX(6)}\end{array}$ \\
\hline 12 & $\mathrm{~F}$ & 90 & OA & THA & $\begin{array}{l}\text { Hip pain, } \\
\text { fistula }\end{array}$ & $\begin{array}{l}\text { Enterococcus } \\
\text { faecalis }\end{array}$ & 57 & 2 weeks & $\operatorname{VCM}(2)$ & 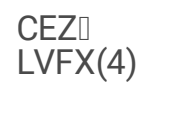 \\
\hline
\end{tabular}


Pre-operative hip aspiration and standard microbiologic (aerobic and anaerobic) culture were performed in all patients. In 12 aspirates, the culprit bacterium was identified in all but one sample. In eight patients (9 hips), microorganisms were Staphylococcus aureus, including methicillin-resistance S. aureus (one hip). In two patients, the causative microorganism was Escherichia coli, and Enterococcus faecalis and an unknown microorganism were the causative agents in one patient each. One patient in whom no bacteria were detected showed the presence of purulent fluid and pus during pre-operative hip aspiration and intra-operative findings. We diagnosed PJI based on clinical and intra-operative macroscopic and histological findings. We assumed that the reason for the negative culture was that the patient was taking sulfamethoxazole trimethoprim regularly after kidney transplant.

Four patients (five hips) had symptoms of infection for less than 3 weeks, whereas eight patients had symptoms of infection for more than 3 weeks (Table 2).

\section{Surgery}

Open debridement was performed using the previous incision and approach. Synovectomy with all abscessed and necrotic joint and periprosthetic regions was performed via large regions (i.e., the anterior, posterior, superior, and inferior regions), with thorough lavage using antibiotic-laden saline. The implant was dislocated in order to treat all interfaces and was then tested pre-operatively for loosening. The modular components (including the femoral head and acetabular insert) and loosening component were replaced, whereas the fixed components were retained. Ten patients (11 hips) underwent exchange of the liner and head, excluding the first two patients. In one patient, the cup component was exchanged because of loosening, but the stem component was retained (Table 3). 
Table 3

Clinical results with the antibiotic-impregnated CHA for the treatment of PJI

\begin{tabular}{|c|c|c|c|c|c|c|}
\hline Case & Reimplantation & $\begin{array}{l}\text { Success / } \\
\text { Failure }\end{array}$ & $\begin{array}{l}\text { Treatment of } \\
\text { reinfection }\end{array}$ & Follow-up & $\begin{array}{l}\text { Follow up periods after } \\
\text { treatment of PJI (years) }\end{array}$ & $\begin{array}{l}\text { Final JOA } \\
\text { score }\end{array}$ \\
\hline ? & $\begin{array}{l}\text { DAIR + } \\
\text { exchange }\end{array}$ & Success & & $\begin{array}{l}\text { Died of other } \\
\text { causes }\end{array}$ & 5.7 & \\
\hline 2 & DAIR & Success & & $\begin{array}{l}\text { Died of other } \\
\text { causes }\end{array}$ & 4.7 & \\
\hline 3 & DAIR & Success & & $\begin{array}{l}\text { Regularly } \\
\text { visits }\end{array}$ & 18.6 & 49 \\
\hline 4 & $\begin{array}{l}\text { DAIR + } \\
\text { exchange }\end{array}$ & $\begin{array}{l}\text { Failure } \\
\text { (Reinfection) }\end{array}$ & $\begin{array}{l}\text { 2-stage } \\
\text { revision }\end{array}$ & $\begin{array}{l}\text { Regularly } \\
\text { visits }\end{array}$ & 16.4 & 59 \\
\hline 5 & $\begin{array}{l}\text { DAIR + } \\
\text { exchange }\end{array}$ & $\begin{array}{l}\text { Failure } \\
\text { (Reinfection) }\end{array}$ & $\begin{array}{l}\text { 2-stage } \\
\text { revision }\end{array}$ & $\begin{array}{l}\text { Died of other } \\
\text { causes }\end{array}$ & 12.5 & 46 \\
\hline 6 & $\begin{array}{l}\text { DAIR + } \\
\text { exchange }\end{array}$ & Success & & $\begin{array}{l}\text { Regularly } \\
\text { visits }\end{array}$ & 11.6 & 42 \\
\hline 7 & $\begin{array}{l}\text { DAIR + } \\
\text { exchange }\end{array}$ & Success & & $\begin{array}{l}\text { Regularly } \\
\text { visits }\end{array}$ & 5.3 & 93 \\
\hline 8 & $\begin{array}{l}\text { DAIR + } \\
\text { exchange }\end{array}$ & Success & & $\begin{array}{l}\text { Regularly } \\
\text { visits }\end{array}$ & 9.0 & 77 \\
\hline 8 & $\begin{array}{l}\text { DAIR + } \\
\text { exchange }\end{array}$ & Success & & $\begin{array}{l}\text { Regularly } \\
\text { visits }\end{array}$ & 9.0 & 78 \\
\hline 9 & $\begin{array}{l}\text { DAIR + } \\
\text { exchange }\end{array}$ & Success & & $\begin{array}{l}\text { Regularly } \\
\text { visits }\end{array}$ & 4.6 & 97 \\
\hline 10 & $\begin{array}{l}\text { DAIR + } \\
\text { exchange }\end{array}$ & Success & & $\begin{array}{l}\text { Died of other } \\
\text { causes }\end{array}$ & 4.0 & 93 \\
\hline 11 & $\begin{array}{l}\text { DAIR + } \\
\text { exchange }\end{array}$ & Success & & $\begin{array}{l}\text { Regularly } \\
\text { visits }\end{array}$ & 3.0 & 77 \\
\hline 12 & $\begin{array}{l}\text { DAIR + } \\
\text { exchange }\end{array}$ & Success & & $\begin{array}{l}\text { Regularly } \\
\text { visits }\end{array}$ & 2.9 & 51 \\
\hline
\end{tabular}

All patients underwent DAIR with antibiotic-impregnated CHA applied to the surrounding bone (Fig. 1B). CHA (Bone Ceram P; Olympus Terumo Biomaterials Corp, Tokyo, Japan) in cylindrical shapes was sintered at $1200^{\circ} \mathrm{C}$ with a porosity of $30-40 \%$; the diameter of micropores was between 40 and $150 \mu \mathrm{m}$. There were two sizes, large and small; the small size (10 mm in diameter and $10 \mathrm{~mm}$ in height) was used for DAIR. During the operation, the selected antibiotic powder was packed into a central cylindrical cavity ( $7 \mathrm{~mm}$ in diameter and $8 \mathrm{~mm}$ deep) in each porous block, and the cavity was then sealed with a CHA plug (7 $\mathrm{mm}$ in diameter and $3 \mathrm{~mm}$ in height). The typical amount of antibiotics in each ceramic block ranged from 60 to $80 \mathrm{mg}$. The amount of the antibiotic powder depended on the type of antibiotic used. The types of antibiotics that were used to impregnate the $\mathrm{CHA}$ are listed in Table 2. In nine patients (10 hips), vancomycin hydrochloride (VCM) was used as the antibiotic for impregnation in the CHA. We created bone holes on the major trochanter and the acetabulum using an air drill. Antibioticimpregnated $\mathrm{CHAs}$ were implanted as often as possible when there were few bone stocks because of severe bone loss. We implanted 2-5 antibiotic-impregnated CHAs in bone holes.

\section{Antibiotherapy}

Pre-operative antibiotherapy was systematically initiated following pre-operative hip aspiration. This treatment consisted of intravenous (i.v.) antibiotherapy at the effective dose, which was quickly adapted based on the aspiration findings. CHA was administered as local antibiotherapy, and i.v. antibiotherapy was maintained for 4-9 weeks, followed by oral administration for 6 weeks. Tolerance was satisfactory. 


\section{Evaluation of outcomes}

The primary outcome measure was the presence or absence of PJI at the most recent clinical follow-up and the final follow-up date. At the most recent follow-up visit, the patients were clinically assessed, and blood tests were performed, including analysis of erythrocyte sedimentation rate and C-reactive protein.

Functional outcomes were assessed based on the Japanese Orthopaedic Association (JOA) hip score, with a maximum score of 100 points (representing no disability).

\section{Success criterion}

The criterion for success was apparent resolution of the initial infection after a minimum follow up of 2 years, defined as absence of clinical, biological, and radiological implant infection signs or death directly related to the infection or treatment [8]. Treatment success was defined as the absence of infection after 2 years, with retention of the prosthesis.

\section{Results}

\section{Treatment outcomes}

The average duration of follow-up was 8.3 years (range, 2.9-18.6 years). No patients were lost to follow-up. Four patients included in this study died of other causes, with an average follow-up of $6.7(4.0-12.5)$ years before death. There was no evidence of recurrent infections in these four patients.

Ten of 12 patients (11 of 13 hips) were successfully treated with no signs of infection at most recent latest follow-up. In two of 12 patients (two of 13 hips) for whom treatment failed, infection was successfully treated with two-stage re-implantation with antibiotic-impregnated CHA. Both patients had diabetes mellitus and had symptoms of infection for more than 3 weeks. However, six of eight patients who showed symptoms of infection for more than 3 weeks were successfully treated with DAIR with antibiotic-impregnated CHA. Eighty-five percent of patients were successfully treated by DAIR with antibiotic-impregnated CHA. No complications, such as excessive postoperative drainage, erythema, bone damage from friction, or any particle disease, were observed following treatment with this antibiotic-impregnated CHA. However, one patient had a greater trochanteric fracture after PJI surgery. There was no pain or dysfunction in this patient, and he was followed up normally. These patients were free of infection at the time of the most recent follow-up. Radiographically, there was no loosening or migration of the components in all 12 patients.

\section{Functional outcomes}

Ten of 12 patients (11 of 13 hips) were comprehensively rated using JOA hip scores at the most recent follow-up. Overall, the median and mean JOA hip scores were 77 and 69.3 (42-97), respectively. For two hips (two patients) who underwent two-stage revision, the JOA hip scores were 59 and 46.

\section{Discussion}

Total joint arthroplasty is a widely used treatment modality for advanced osteoarthritis of the hip and knee. Although this procedure is highly successful, PJI is a relatively uncommon but devastating complication following total joint arthroplasty. The average reported incidence of PJI is $0.5-2 \%$ [9-11]. PJI has a negative impact on the patient and can cause significant morbidity, mortality, leading to massively increased healthcare costs $[9,12,13]$.

Various risk factors, including rheumatoid arthritis, diabetes mellitus, malignancy, obesity, and immunosuppressant drug use, are associated with the occurrence of PJI [14, 15]. Revision surgery also increases the risk of PJI [15] and is associated with a higher mortality risk, suggesting that there may be an association between PJI and mortality $[12,13]$.

Primary surgical management strategies for PJI differ among institutions but include DAIR, one-stage revision arthroplasty, and two-stage revision arthroplasty. However, two-stage revision is associated with significant morbidity and mortality and is poorly 
tolerated by patients. Additionally, when associated with a period without a hip implant, the tissue changes can lead to important functional deficits after re-implantation [16].

In appropriate patients, single-stage revision appears to be associated with similar reinfection rates when compared with twostage revision with superior functional outcomes [17]. One option for the surgical treatment for early PJI is DAIR, which is considered a less invasive surgical treatment option than revision surgery owing to the preservation of bone stock, shorter duration of the surgical procedure, decreased risk of intra-operative fractures, and faster postoperative rehabilitation [5]. Moreover, DAIR offers the benefits of decreased patient morbidity and may decrease healthcare costs compared with 2-stage revision arthroplasty; however, the reported outcomes are heterogeneous, concerning, and suggest more detailed considerations. The rates of clinical cure after DAIR are highly variable, ranging from $37-88 \%$, with the average success rate being reported at around $50 \%[18-23]$.

Multiple factors influence the outcomes of DAIR. For example, the causative microorganisms, applied antimicrobial regimen, soft tissue envelope, timing of intervention, and duration of symptoms have all been shown to influence the outcome of DAIR [19-22]. Other considerations include host-related factors (the patient's overall health status, medical comorbidities, and immune status), and implant-related factors (implant stability and fixation) [21].

Moreover, several studies have demonstrated that the DAIR failure rate increases when the infection persists for a longer period of time $[19,22,23]$. In chronic infections, implant retention is rarely successful. Implant removal leaves the patient disabled for weeks or even months [13]. Moreover, once a mature biofilm has developed, the infection cannot be cured without removing the implant $[24,25]$. Thus, the reason for the historically high failure rates of irrigation and debridement with component retention alone could be explained by the persistence of biofilm in PJI.

Indications for determining eligibility for DAIR have been suggested in recent years as the arthroplasty community has developed a greater understanding of the risk factors that predispose patients to treatment failure. Success can be achieved in over $70 \%$ of cases when patients with favorable factors are selected, such as those with short duration of symptoms (less than 3-4 weeks), a stable implant, and healthy soft tissues surrounding the prosthesis $[9,20,26]$. For this reason, the Infectious Diseases Society of America published guidelines in 2013 recommending removal of the implant when PJI develops more than 30 days after the index arthroplasty [9].

In this retrospective study, we investigated the efficacy of antibiotic-impregnated CHA used in conjunction with irrigation and debridement for the treatment of PJI with attempted prosthetic retention for determination of long-term efficacy and safety. PJI could be treated successful using antibiotic-impregnated CHA, even for more advanced cases. All patients with infective symptoms for less than 3 weeks were successfully treated with DAIR using antibiotic-impregnated CHA. Moreover, six of eight patients who had symptoms of infection for more than 3 weeks were successfully treated by DAIR with antibiotic-impregnated CHA. The success of DAIR in early PJI largely depends on the presence of a mature biofilm. Infected artificial joints are often unresponsive to antibiotic treatment owing to poor vascular supply and biofilm formation. In most cases, reconstruction was performed with cemented implants, and antibiotic-impregnated cement was used. At revision surgery with the cemented prosthesis, the success rate with antibiotic-impregnated bone cement has been reported to be higher than that without antibiotic-impregnated bone cement [27]. However, during PJI surgery with a cementless prosthesis, a high concentration of antibiotics cannot be obtained around the prosthesis.

Previous studies, including our study, reported successful two-stage reconstruction surgery using CHA in patients with intractable PJI, with good clinical outcomes without any cases of reinfection during follow-up [28, 29]. Importantly, our results showed that this novel antibiotic delivery system could be a useful tool for PJI surgery with cementless prosthesis. In a previous study by Sudo et al., antibiotic-impregnated $\mathrm{CHA}$ has been suggested as an approach for improving outcomes by providing a local antibiotic depot [28]. Shinto et al. first utilized CHA for the local delivery of antibiotics and demonstrated that antibioticimpregnated CHA releases gentamicin sulfate, cefoperazone sodium, and flomoxef sodium for longer period than antibioticloaded polymethylmethacrylate (PMMA) cement (ALAC) in vivo and in vitro [6]. Moreover, in vitro, gentamicin-impregnated CHA was reported to produce 2.5 times higher concentrations, for 1.2 times longer, than an ALAC drug delivery system [30]. Gentamicin-impregnated CHA ceramic was also shown to have the ability to deliver 5 times the minimum inhibitory

Page $8 / 13$ 
concentrations for Staphylococcus species for at least 12 weeks. A recent in vitro study demonstrated that antibioticimpregnated CHA releases active VCM for longer periods and in higher amounts than ALAC [29]. Additionally, this drug delivery system is very simple and easy to use. Any antibiotic can be selected according to the sensitivities of the microorganism. We applied this CHA in the major trochanter and acetabulum during PJI surgery. All impregnated antibiotics are thereafter released over a long period of time. Based on our findings, we suggest that this new drug delivery system may be a useful tool for revision surgery using a cementless prosthesis. Moreover, this $\mathrm{CHA}$ ceramic was fully biocompatible with bone and marrow cells, which grow into the pores.

We believe that antibiotic-impregnated CHA may also be useful for cemented prosthesis. When ALAC and antibioticimpregnated CHA are used as combined treatment for PJI, enhanced antibacterial effects may be obtained.

There were several limitations to the current study. First, this study was retrospective, and randomized trials are needed to conclusively determine whether the use of CHA could improve infection-free survival when used as part of an attempt at implant retention in the setting of PJI. Furthermore, because the study was retrospective in nature, it is possible that there may have been some selection bias owing to selection of CHA in more challenging cases. Second, in early PJI, there may be cases that can be treated with only DAIR. However, recurrent infection may be a physical and mental burden on patients. Therefore, antibioticimpregnated $\mathrm{CHA}$ can be used to lower the possibility of recurrence. Finally, our study cohort lacked a direct control group to compare irrigation and debridement with component retention with or without the addition of antibiotic-impregnated $\mathrm{CHA}$.

\section{Conclusion}

In this study, $85 \%$ of hips were successfully treated by DAIR with antibiotic-impregnated CHA with a mean follow up of 8.2 years. No complications with CHA were observed. Thus, our findings suggested that DAIR treatment with antibiotic-impregnated CHA produced high success rates for the treatment of PJI after THA, even in cases of advanced disease, with adequate functional outcomes after surgery. Accordingly, we propose the use of retention treatment as an initial treatment option in selected cases of PJI after THA.

\section{Abbreviations}

PJI

periprosthetic joint infection

THA

total hip arthroplasty

DAIR

debridement, antibiotics, irrigation, and retention

$\mathrm{CHA}$

calcium hydroxyapatite

VCM

vancomycin hydrochloride

i.v.

intravenous

JOA

the Japanese Orthopaedic Association

ALAC

antibiotic-loaded polymethylmethacrylate cement

\section{Declarations}

\section{Acknowledgements}


Not applicable.

\section{Author information}

\section{Affiliations}

Mie University Graduate School of Medicine, 2-174 Edobashi, Tsu, Mie 514-8507, Japan

Hiroki Wakabayashi, Masahiro Hasegawa, Yohei Naito, Shine Tone \& Akihiro Sudo

\section{Contributions}

$\mathrm{HW}, \mathrm{YN}$, and ST contributed to the data collection and analysis. All patients underwent surgery by AS and MH. HW, MH and AS have contributed majorly in writing the manuscript. All authors read and approved the final manuscript.

\section{Corresponding author}

Correspondence to Hiroki Wakabayashi.

\section{Ethics declarations}

This study was approved by the institutional review board of our institution (Mie University Graduate School of Medicine).

\section{Consent for publication}

Not applicable.

\section{Competing interests}

All authors declare that they have no competing interests.

\section{Funding}

No funding was required for this study.

\section{References}

1. Kirkpatrick DK, Trachtenberg LS, Mangino PD, Von Fraunhofer JA, Seligson D. In vitro characteristics of tobramycin-PMMA beads: comprehensive strength and leaching. Orthopedics. 1985;8:1130-3

2. Cerretani D, Giorgi G, Fornara P, Bocchi L, Neri L, Ceffa R, et al. The in vitro elution characteristics of vancomycin combined with imipenem-cilastatin in acrylic bone-cements. J Arthroplasty. 2002;17:619-26.

3. Bozic KJ, Ries MD. The impact of infection after total hip arthroplasty on hospital and surgeon resource utilization. J Bone Joint Surg Am. 2005;87:1746-51.

4. Klouche S, Sariali E, Mamoudy P. Total hip arthroplasty revision due to infection: a cost analysis approach. Orthop Traumatol Surg Res. 2010;96:124-32.

5. Fisman DN, Reilly DT, Karchmer AW, Goldie SJ. Clinical effectiveness and cost-effectiveness of 2 management strategies for infected total hip arthroplasty in the elderly. Clin Infect Dis. 2001 1;32:419-30.

6. Shinto Y, Uchida A, Korkusuz F, Araki N, Ono K. Calcium hydroxyapatite ceramic used as a delivery system for antibiotics. J Bone Joint Surg Br. 1992;74:600-4. 
7. Uchida A, Shinto Y, Araki N, Ono K. Slow release of anticancer drugs from porous calcium hydroxyapatite ceramic. J Orthop Res. 1992;10:440-5.

8. Klouche S, Lhotellier L, Mamoudy P. Infected total hip arthroplasty treated by an irrigation-debridement/component retention protocol. A prospective study in a 12-case series with minimum 2 years' follow-up. Orthop Traumatol Surg Res. 2011;97:134-8

9. Zimmerli W, Trampuz A, Ochsner PE. Prosthetic-Joint Infections. N Engl J Med. 2004 14;351:1645-54

10. Osmon DR, Berbari EF, Berendt AR, Lew D, Zimmerli W, Steckelberg JM, et al. Infectious Diseases Society of America. Executive summary: Diagnosis and management of prosthetic joint infection: Clinical practice guidelines by the Infectious Diseases Society of America. Clin Infect Dis. 2013;56:1-10.

11. de Vries L, van der Weegen W, Neve W, Das H, Ridwan B, Steens J. The Effectiveness of Debridement, Antibiotics and Irrigation for Periprosthetic Joint Infections after Primary Hip and Knee Arthroplasty. A 15 Years Retrospective Study in Two Community Hospitals in the Netherlands. J Bone Jt Infect. 2016 7;1:20-24.

12. Zmistowski B, Karam JA, Durinka JB, Casper DS, Parvizi J. Periprosthetic joint infection increases the risk of one-year mortality. J Bone Joint Surg Am. 2013 18;95:2177-84

13. Natsuhara KM, Shelton TJ, Meehan JP, Lum ZC. Mortality During Total Hip Periprosthetic Joint Infection. J Arthroplasty. 2019;34:S337-S342.

14. Choong PF, Dowsey MM, Carr D, Daffy J, Stanley P. Risk factors associated with acute hip prosthetic joint infections and outcome of treatment with a rifampinbased regimen. Acta Orthop. 2007;78:755-65.

15. Bongartz T, Halligan CS, Osmon DR, Reinalda MS, Bamlet WR, Crowson CS, et al. Incidence and risk factors of prosthetic joint infection after total hip or knee replacement in patients with rheumatoid arthritis. Arthritis Rheum. 2008 15;59:1713-20.

16. Berend KR, Lombardi AV Jr, Morris MJ, Bergeson AG, Adams JB, Sneller MA. Two-stage treatment of hip periprosthetic joint infection is associated with a high rate of infection control but high mortality. Clin Orthop Relat Res. 2013;471:510-8.

17. Leonard HA, Liddle AD, Burke O, Murray DW, Pandit H. Single- or two-stage revision for infected total hip arthroplasty? A systematic review of the literature. Clin Orthop Relat Res. 2014;472:1036-42.

18. Shohat N, Goswami K, Tan TL, Fillingham Y, Parvizi J. Increased Failure After Irrigation and Debridement for Acute Hematogenous Periprosthetic Joint Infection J Bone Joint Surg Am. 2019 17;101:696-703.

19. Triantafyllopoulos GK, Poultsides LA, Sakellariou VI, Zhang W, Sculco PK, Ma Y, et al. Irrigation and debridement for periprosthetic infections of the hip and factors determining outcome. Int Orthop. 2015;39:1203-9.

20. Vilchez F, Martínez-Pastor JC, García-Ramiro S, Bori G, Maculé F, Sierra J, et al. Outcome and predictors of treatment failure in early post-surgical prosthetic joint infections due to Staphylococcus aureus treated with debridement. Clin Microbiol Infect. 2011;17:439-44.

21. Odum SM, Fehring TK, Lombardi AV, Zmistowski BM, Brown NM, Luna JT, et al. Periprosthetic Infection Consortium. Irrigation and debridement for periprosthetic infections: does the organism matter? J Arthroplasty. 2011;26(6 Suppl):114-8.

22. Kuiper JW, Vos SJ, Saouti R, Vergroesen DA, Graat HC, Debets-Ossenkopp YJ, et al. Prosthetic joint-associated infections treated with DAIR (debridement, antibiotics, irrigation, and retention): analysis of risk factors and local antibiotic carriers in 91 patients Acta Orthop. 2013;84:380-6.

23. Buller LT, Sabry FY, Easton RW, Klika AK, Barsoum WK. The preoperative prediction of success following irrigation and debridement with polyethylene exchange for hip and knee prosthetic joint infections. J Arthroplasty. 2012;27:857-64.e1-4. 
24. Lebeaux D, Ghigo JM, Beloin C. Biofilm-related infections: bridging the gap between clinical management and fundamental aspects of recalcitrance toward antibiotics. Microbiol Mol Biol Rev 2014;78:510-43.

25. Davies D. Understanding biofilm resistance to antibacterial agents. Nat Rev Drug Discov 2003;2:114-22.

26. Byren I, Bejon P, Atkins BL, Angus B, Masters S, McLardy-Smith P, et al. One hundred and twelve infected arthroplasties treated with 'DAIR' (debridement, antibiotics and implant retention): antibiotic duration and outcome. J Antimicrob Chemother. 2009;63:1264-71.

27. Joseph TN, Chen AL, Di Cesare PE. Use of antibiotic-impregnated cement in total joint arthroplasty. J Am Acad Orthop Surg. 2003;11:38-47.

28. Sudo A, Hasegawa M, Fukuda A, Uchida A. Treatment of infected hip arthroplasty with antibiotic-impregnated calcium hydroxyapatite. J Arthroplasty. 2008;23:145-50.

29. Choe H, Inaba Y, Kobayashi N, Miyamae Y, Ike H, Saito T. Clinical utility of antibiotic-loaded hydroxyapatite block for treatment of intractable periprosthetic joint infection and septic arthritis of the hip. Mod Rheumatol. 2015; 25:937-42.

30. Korkusuz F, Uchida A, Shinto Y, Araki N, Inoue K, Ono K. Experimental implant-related osteomyelitis treated by antibioticcalcium hydroxyapatite ceramic composites. J Bone Joint Surg Br. 1993; 75:111-4.

\section{Figures}




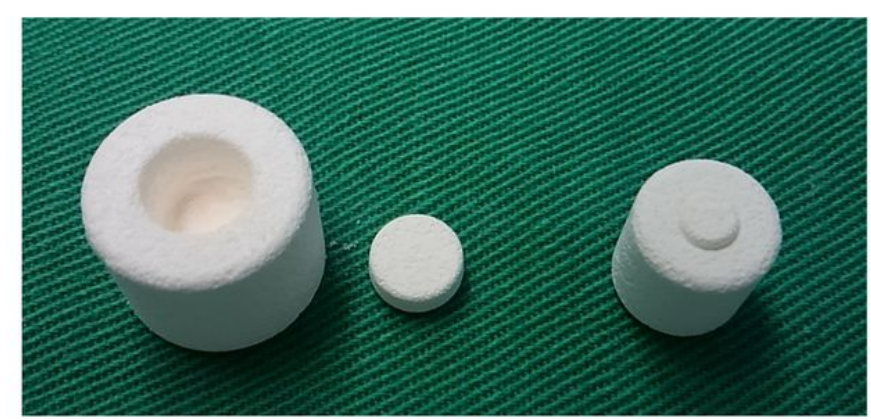

a

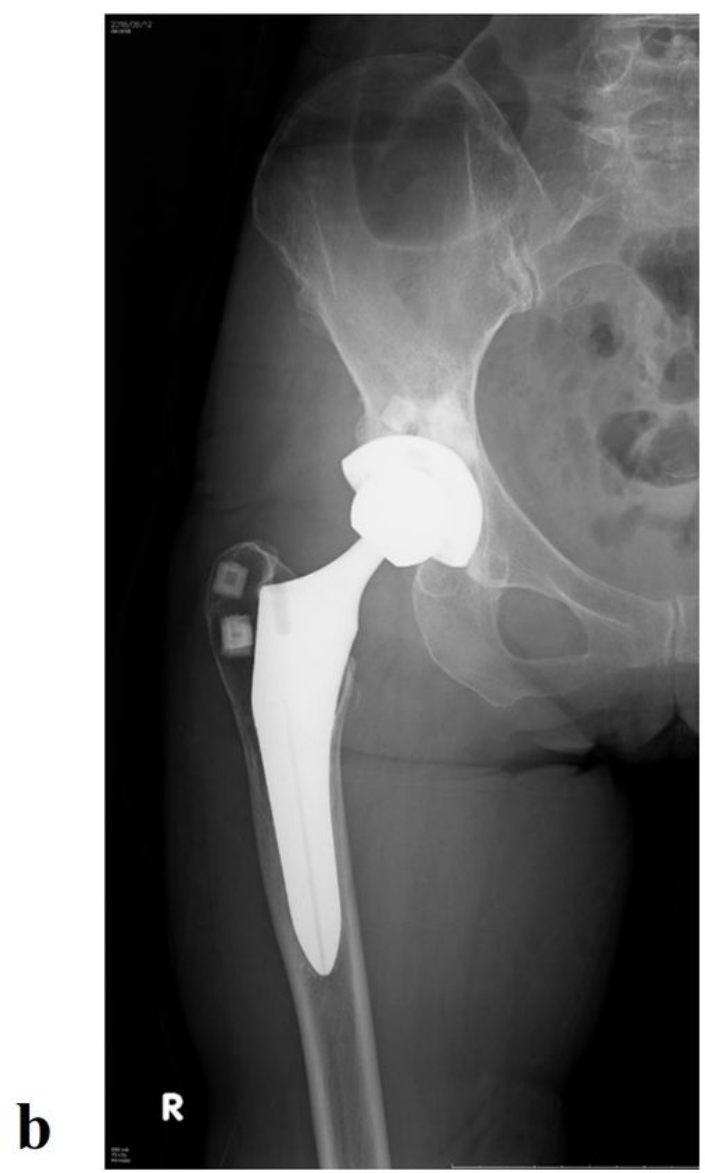

\section{Figure 1}

A: Photograph of a calcium hydroxyapatite (CHA) ceramic block. B: Radiographs of the right hip of a 64-year-old woman. Anteroposterior radiograph after revision total hip arthroplasty with $\mathrm{CHA}$ blocks placed into the major trochanter and acetabulum is shown. 